\title{
Linear lepidopteran ambidensovirus 1 sequences drive random integration of a reporter gene in transfected Spodoptera frugiperda cells
}

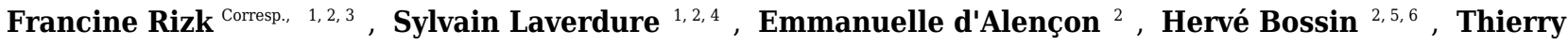 \\ Dupressoir Corresp. 1,2 \\ 1 EPHE, PSL Research University, UMR 1333 DGIMI, Université de Montpellier, Montpellier, France \\ 2 UMR 1333 DGIMI INRA/UM, Université de Montpellier, Montpellier, France \\ 3 Department of Life and Earth Sciences, Faculty of Sciences, Branch II, Innovative Therapeutic Laboratory, Lebanese University, Beirut, Lebanon \\ 4 Laboratory of Human Retrovirology and Immunoinformatics (LHRI), Leidos Biomedical Research Clinical Services Program, National Cancer Institute, \\ Frederick, United States of America \\ 5 Laboratoire d'Entomologie Médicale, Institut Louis Malardé, Papeete, French Polynesia \\ 6 Aix Marseille Univ, IRD, AP-HM, SSA, VITROME, IHU-Méditerranée infection, Marseille, France \\ Corresponding Authors: Francine Rizk, Thierry Dupressoir \\ Email address: francinerizk@gmail.com, thierry.dupressoir@ephe.sorbonne.fr
}

Background. The Lepidopteran ambidensovirus 1 isolated from Junonia coenia (hereafter JcDV) is an invertebrate parvovirus considered as a viral transduction vector as well as a potential tool for the biological control of insect pests. Previous works showed that JcDV-based circular plasmids experimentally integrate into insect cells genomic DNA.

Methods. In order to approach the natural conditions of infection and possible integration, we generated linear JcDV-gfp based molecules which were transfected into non permissive Spodoptera frugiperda (Sf9) cultured cells. Cells were monitored for the expression of GFP and DNA was analysed for integration of transduced viral sequences. Non-structural protein modulation of the VP-gene cassette promoter activity was additionally assayed.

Results. We show that linear JcDV-derived molecules are capable of long term genomic integration and sustained transgene expression in Sf9 cells. As expected, only the deletion of both inverted terminal repeats (ITR) or the polyadenylation signals of NS and VP genes dramatically impairs the global transduction/expression efficiency. However, all the integrated viral sequences we characterized appear "scrambled" whatever the viral content of the transfected vector. Despite a strong GFP expression, we were unable to recover any full sequence of the original constructs and found rearranged viral and nonviral sequences as well. Cellular flanking sequences were identified as non-coding ones. On the other hand, the kinetics of GFP expression over time led us to investigate the apparent down-regulation by non-structural proteins of the VP-gene cassette promoter.

Conclusions. Altogether, our results show that JCDV-derived sequences included in linear DNA molecules are able to drive efficiently the integration and expression of a foreign gene into the genome of insect cells, whatever their composition, provided that at least one ITR is present. However, the transfected sequences were extensively rearranged with cellular DNA during or after random integration in the host cell genome. Last, the non-structural proteins seem to participate in the regulation of $p 9$ promoter activity rather than to the integration of viral sequences. 


\section{Linear lepidopteran ambidensovirus 1 sequences drive random integration of a reporter}

\section{2 gene in transfected Spodoptera frugiperda cells}

3 Francine Rizk ${ }^{1,2, \$ *}$, Sylvain Laverdure ${ }^{1,2, \$}$, Emmanuelle d'Alençon ${ }^{2}$, Hervé Bossin ${ }^{2, \$}$ and

4 Thierry Dupressoir ${ }^{1,2 *}$.

5 *Corresponding author

6 Email: Thierry.Dupressoir@ephe.sorbonne.fr

$7{ }^{1}$ EPHE, PSL Research University, UMR 1333 DGIMI - Université de Montpellier, Montpellier,

8 France

$9 \quad 2$ UMR 1333 DGIMI INRA/UM - Université de Montpellier, Montpellier, France

$11 *$ Corresponding author

12 Francine Rizk

13 Email: francinerizk@gmail.com

$14{ }^{1}$ EPHE, PSL Research University, UMR 1333 DGIMI - Université de Montpellier, Montpellier,

15 France

$16{ }^{2}$ UMR 1333 DGIMI INRA/UM2 - Université de Montpellier, Montpellier, France

$17 \$$ present address: Department of Life and Earth Sciences, Faculty of Sciences, Branch II,

18 Innovative Therapeutic Laboratory, Lebanese University, Beirut, Lebanon

20 Sylvain Laverdure ${ }^{1,2}$

$21 \$$ present address: Laboratory of Human Retrovirology and Immunoinformatics

22 (LHRI), Leidos Biomedical Research 
23 Clinical Services Program, National Cancer Institute

24 Frederick, United States of America

25

26 Emmanuelle d'Alençon ${ }^{2}$

$27 \quad 2$ UMR 1333 DGIMI INRA/UM - Université de Montpellier, Montpellier, France

28

29 Hervé Bossin $^{2}$

30 \$ present address: Laboratoire d'Entomologie Médicale, Institut Louis Malardé, Papeete, French

31 Polynesia. Aix Marseille Univ, IRD, AP-HM, SSA, VITROME, IHU-Méditerranée infection,

32 Marseille, France

33

35 Words in text: 6142

36 Words in Summary: 318

37 Tables: 1

38 Figures:7 


\section{Abstract}

40 Background. The Lepidopteran ambidensovirus 1 isolated from Junonia coenia (hereafter

$\mathrm{JcDV}$ ) is an invertebrate parvovirus considered as a viral transduction vector as well as a potential tool for the biological control of insect pests. Previous works showed that JcDV-based circular plasmids experimentally integrate into insect cells genomic DNA.

Methods. In order to approach the natural conditions of infection and possible integration, we generated linear JcDV-gfp based molecules which were transfected into non permissive Spodoptera frugiperda (Sf9) cultured cells. Cells were monitored for the expression of GFP and DNA was analysed for integration of transduced viral sequences. Non-structural protein modulation of the VP-gene cassette promoter activity was additionally assayed.

Results. We show that linear JcDV-derived molecules are capable of long term genomic integration and sustained transgene expression in $S f 9$ cells. As expected, only the deletion of both inverted terminal repeats (ITR) or the polyadenylation signals of $N S$ and $V P$ genes dramatically impairs the global transduction/expression efficiency. However, all the integrated viral sequences we characterized appear "scrambled" whatever the viral content of the transfected vector. Despite a strong GFP expression, we were unable to recover any full sequence of the original constructs and found rearranged viral and non-viral sequences as well. Cellular flanking sequences were identified as non-coding ones. On the other hand, the kinetics of GFP expression over time led us to investigate the apparent down-regulation by non-structural proteins of the VP-gene cassette promoter.

Conclusions. Altogether, our results show that JcDV-derived sequences included in linear DNA molecules are able to drive efficiently the integration and expression of a foreign gene into the genome of insect cells, whatever their composition, provided that at least one ITR is present. 
62 However, the transfected sequences were extensively rearranged with cellular DNA during or

63 after random integration in the host cell genome. Last, the non-structural proteins seem to

64 participate in the regulation of $\mathrm{p} 9$ promoter activity rather than to the integration of viral

65 sequences.

66

67 Introduction

68 Ambidensoviruses belong to the Parvoviridae family, a group of small, non-enveloped viruses

69 with icosahedral symmetry and a linear genome of 4-6kb single-stranded (ss) DNA.

70 Parvoviridae are divided into two subfamilies, depending upon whether they infect vertebrates

71 (Parvovirinae), or invertebrates (Densovirinae, DNV). The latter currently include 15 virus

72 species, divided into five genera, Ambidensovirus, Brevidensovirus, Hepandensoviruses,

73 Iteradensovirus and Penstyldensovirus \{Cotmore, $2013 \# 2\}$ even if that classification will

74 probably be modified after the finding of echinoderm-infecting "densoviruses" \{Hewson, 2014

$75 \# 75\}$. DNVs, like other members of the Parvovirus genus, are autonomously replicating viruses

76 and differ in this respect from members of the genus Dependoparvovirus which need helper

77 functions for replication. The DNV isolated from the lepidoptera Junonia coenia belongs to the

78 species Lepideptoran ambidensovirus and will be named JcDV hereafter. JcDV (Junonia coenia

79 densovirus, isolate Oxford, GenBank: KC883978.1) has a 6032 nucleotides genome with

80 identical 547 nucleotides inverted terminal repeats (ITR). It exhibits an ambisense genomic

81 organization, the non-structural $(N S)$ and structural $(V P)$ genes being positioned in the 5'-half of

82 each complementary strand after conversion of the single-stranded infectious genome in a

83 double-stranded replicating genome. Each strand is encapsidated separately and converted into

84 double-stranded DNA after infection (Dumas et al. 1992). The JcDV genome ambisense 
85 organization displays a major open reading frame (ORF1) encoding four capsid proteins VP1 to

86 VP4, the expression of which is under the control of the VP-gene cassette promoter, hereafter

87 designated p9, on one strand (Wang et al. 2014), and three ORFs coding for replication proteins

88 NS-1, NS-2 and NS-3 are located on the complementary strand and controlled by the NS-gene

89 cassette promoter, traditionally designated p93 promoter (Wang et al. 2014). Those are

90 translated from a $2.4 \mathrm{~kb}$ genomic mRNA (NS-3) and a sub-genomic $1.7 \mathrm{~kb}$ mRNA (NS-1 and NS-

91 2) respectively (Wang et al. 2014).

92 The potential of Densovirinae as biocontrol agents against insect pests has been reported

93 (Belloncik 1990; Bergoin \& Tijssen 1998; Fediere 2000; Tal \& Attathom 1993).

94 Ambidensoviruses, as well as other members of the Densovirinae subfamily, have also been used

95 as gene transfer vehicles to investigate viral pathogenesis and genetic manipulation of insects

96 after integration of plasmidic ambidensovirus vectors either in vitro and in vivo (Afanasiev \&

97 Carlson 2000; Bossin et al. 2003; Bossin et al. 2007; Gu et al. 2011; Royer et al. 2001). On the

98 other hand dependoparvoviruses as well as rodent protoparvovirus 1 DNA molecules were

99 shown to integrate in a foreign DNA after recognition, by the replication proteins, of precise

100 binding and cutting sites shared between target genomic sequence and viral hairpins (Corsini et

101 al. 1997; Hendrie et al. 2003; Janovitz et al. 2013). Last, recent data show that a significant

102 amount of Parvoviridae DNA remnants sign past infections, some of which gave rise to

103 endogenization and expression of viral proteins (Liu et al. 2011). JcDV ITRs as well as

104 non-structural protein 1 (NS1) activities resemble those of "integrative" Parvovirinae (Ding et

105 al. 2002) and could explain the above mentioned integration events of plasmid DNA sequences

106 in vitro and in vivo (Bossin et al. 2003; Bossin et al. 2007; Royer et al. 2001). 
107 In order to evaluate the capacity of linear JcDV sequences, more relevant to infectious viral

108 genome, to integrate within the host DNA, different non-infectious linear constructs

109 encompassing JcDV sequences were transfected into the non-permissive Sf9 cell line. These

110 constructs express the green fluorescent protein (GFP) gene under the control of the JcDV p9

111 promoter, which allowed us to follow the integration and expression of linear JcDV genes. In

112 addition, our observations led us to investigate a possible role of JcDV NS proteins on the

113 activity of the $\mathrm{p} 9$ promoter in vitro.

114 Altogether our results show that defined JcDV-derived sequences brought by linear DNA

115 molecules are able to drive efficiently the integration and expression of a foreign gene into the

116 genome of insect cells. We confirm that, as already described with circular plasmid vectors,

117 some viral sequences - i.e. ITRs and regulatory regions around the polyA signals - are

118 indispensable for a correct expression of the transgene. Some viral integrated sequences as well

119 as their flanking chromosomal regions were analyzed and were interpreted as a randomized

120 integration within repeated or transposable elements and/or intergenic regions. Viral sequences

121 show dramatic rearrangements in all cases and no complete viral genome was recovered from the

122 integrated forms which were characterized. However, our results do not fully sustain the

123 previous assessment that NS proteins expression favours integration at a low copy number in the

124 host genome. In addition, a stable NS gene expression seems to be accompanied by a lower

125 expression of the reporter gene. This result led us to evaluate in vitro a possible trans-regulation

126 of the p9 promoter by the NS proteins, which does not seem to be the case. Our results led us to

127 conclude that a recombinant JcDV virus encompassing only a transgene and an ITR could be

128 sufficient as an integrative expression vector in insect cells. 


\section{Materials and Methods}

$131 \quad$ Plasmids and derived linear molecules

132 Linear molecules were derived from already described JcDV-based plasmids, pJGFPH (pFull)

133 encompassing an infectious sequence of the JcDV genome and pJGFP $\triangle \mathrm{NSH}(\mathrm{pVP})$ with deleted

134 NS genes. For both plasmids the GFP coding sequence and simian virus 40 polyadenylation

135 signal are inserted so as to place the green fluorescent protein (gfp) in frame, 25 codons

136 downstream of the ATG initiation codon for VP4 polypeptide, under the transcriptional control

137 of the P9 viral promoter (Bossin et al. 2003) . pHp9GFPNSH (pNS) vector displays the genuine

$138 g f p$ start codon 23 nucleotides downstream p9 TATA box.

139 For the measurement of the p9 promoter activity, the reporter plasmid (pHp9LUC-DNS) was

140 obtained as follows: pFull was digested with NdeI then re-ligated to eliminate the p93 promoter

141 and most of the NS proteins coding sequence. The $g f p$ was then replaced with firefly luciferase

142 gene (Luc), amplified from the pGL3 basic vector (Promega) with the primers

143 5'-TGTTGGTAAAGCCACCATGGAAG-3' (sense) and

144 5'-CTCGAAGCGGGCGGCCGCCCCGACTCTAG-3' (antisense)

145 using a high fidelity polymerase (Platinum Taq DNA Polymerase, Invitrogen). A transfection

146 control expressing the Renilla reniformis luciferase (Nalcacioglu et al. 2003) under the control of

147 the IE1 promoter of Autographa californica Nucleopolyhedrovirus (AcNPV) (kind gift of Just

148 Vlak, Wageningen University, Netherlands) was used as a "relative transfection control" of

149 transduction efficiencies. Co-transfections were performed with JetPEI (Polyplus Transfection)

150 and luciferase activity was revealed using the Dual Luciferase Promoter Assay System

151 (Promega) and quantified on a Berthold Centro LB 960 luminometer. 
152 A3GFP plasmid was derived from A3-LacZ construct (Mange et al. 1997) after replacement of

153 the $l a c Z$ gene sequence with the corresponding $g f p$ one (thanks to F.X. Jousset, INRA).

154 Linear molecules were obtained after proper restriction of $10 \mu \mathrm{g}$ of JcDV-based pFull, pNS and 155 pVP vectors. DNA was cut as indicated in Figure 1 with restriction enzymes ClaI, PvuII, XcmI, 156 AflII, MspA1L, and PshAI according to the New England Biolabs protocols. ClaI and PvuII cut

157163 nucleotides upstream JcDV's right ITR and 333 nucleotides upstream leftITR respectively in 158 the pBR322 plasmid backbone whereas $X c m$ I cuts 8 nucleotides upstream the p93 TATA box.

159 AflII restriction site deleted the polyadenylation signals (poly-A) which belong to both ORF1 and 160 ORF2/ORF3 in the ambisense organization of JcDV and MspA1L and $P s h \mathrm{AI}$ cut within right 161 and left ITRs at positions 526/5506 and 88/5944 respectively according to the nts numbers in the

162 virus sequence. Restricted DNA was separated on a $0,8 \%$ agarose gel and expected bands were 163 cut out from the gel (NucleoSpin® Extract II kit,

164 Macherey-Nagel). Restricted DNA size and purity were assessed following conventional 165 protocols.

Cell culture and transfection system Sf9 cells (ATCC CRL 1711) derived from S. frugiperda ovaries (Vaughn et al. 1977) were maintained at $28^{\circ} \mathrm{C}$ in $10 \%$ heat-inactivated fetal calf serum (FCS) supplemented TC100 medium.

$1711 \mu \mathrm{g}$ of DNA was used for the transfection of $2.10^{4} \mathrm{Sf} 9$ cells with Jet PEI (Polyplus Transfection)

172 according to the manufacturer's protocol.

173 The number of GFP expressing cells, among 10000 sorted live cells, was measured via

174 fluorescent activated cell sorter (BD FACSCalibur) at 488nm excitation and 530nm emission. 
175 Microscopy was performed with a Nikon MICROPHOT-FXA microscope /ACT-2U software

176 (Nikon).

177 Fluorescent colonies were picked out then amplified to confluence in Sf9-conditioned

178 TC100medium supplemented with 20\% heat-inactivated FCS. Each amplified clonal cell

179 population was diluted and subcloned three times before populations stably expressing GFP were

180 obtained (approximately two clones per initial transfection).

\section{$181 \quad$ DNA analysis}

182 Low molecular weight DNA was extracted according to Ziegler (Ziegler et al. 2004). For

183 genomic DNA analysis, 30 $\mu \mathrm{g}$ of DNA were extracted using standard protocols and restricted

184 with 150U. of the appropriate restriction enzymes. All the restriction enzymes were from New

185 England Biolabs. Restricted DNA was separated on a $0,8 \%$ agarose gel and bands were cut out

186 from the gel (NucleoSpin ${ }^{\circledR}$ Extract II kit, Macherey-Nagel). Size and purity of each DNA

187 fragment were assessed electrophoretically. Digested DNA were prepared for Southern blotting

188 analysis according to conventional methods (Sambrook et al. 1989). Blots were then probed with

189 a full length (pFull restricted with PshAI) probe, either Dig-labelled for episomal DNA analysis,

190 or $\triangle \mathrm{dCT}^{32} \mathrm{P}$-labelled for Southern blot analysis. Hybridizations were performed according to the

191 respective manufacturer's protocols. Radioactive membrane was exposed on a storage phosphor

192 screen and visualized using a Phosphor Imager STORM 840 after 2 or 5 days.

193

$194 \quad$ Statistical analysis

195

196 The percentage of GFP expressing cells from five different measurements at 3, 6, 10,18 and 30

197 days post-transfection was measured. The evolution of the GFP positive cells percentage along 
198 with time was represented with a linear correlation curve $\left(\mathrm{R}^{2}>0.5\right)$ and graphically compared. In

199 addition, a Wilcoxon rank sum test with continuity correction ( $\mathrm{R}$ suite) to the raw fluorescent

200 cells number obtained after transfection of plasmid $v s$. linear JcDV-based vectors at four time

201 points $(6,10,18$ and 30 d. post-transfection, p.t.).

202 Significance of differences in luciferase expression was assessed by a Student test (R suite).

203 PCR and RT-PCR

204 100ng of DNA from each analyzed cell clone was used as a template for direct PCR (see Table I

205 and Figure 1 for primers names, sequences and positions). The $V P$-GFP fusion was assessed with

206 primers located in the $V P l(1)$ and in the C-terminus $V P$ sequence (2) downstream the $g f p$ gene.

207 The right ITR (p9 ITR)-GFP region was examined in clones transfected with pNS-based

208 molecules, using primers located in the p9 ITR (1') and the $g f p$ gene (2'). The NS-GFP region

209 was amplified with primers based in the $g f p$ (3) and NS-3 genes (4). The long p9 ITR-NS region

210 was assessed with primers located in the p9 ITR (1') and the NS-3 (4), using a long range/high

211 fidelity amplification DNA polymerase (Herculase, Stratagene).

212 Total RNA was extracted from cells (NucleoSpin RNA II kit, Macherey-Nagel). The

213 retrotranscription of mRNA was performed using the ThermoScript RT-PCR System kit

214 (Invitrogen). Amplification of the NS transcripts from the cDNA templates was performed using

215 primers located in the $N S-1$ (5) and the untranslated region 5 ' to $N S-3$ (6)

216 PCR were performed on a GeneAmp PCR system 2700, Applied Biosystems, using conditions

217 adapted to the melting temperatures of the primers and expected sizes elongations. 
221 Reverse PCR was performed according to (Ochman et al. 1993). Briefly, 10 $\mu \mathrm{g}$ of cellular DNA

222 was digested with $H p a \mathrm{I} \mathrm{O} / \mathrm{N}$ at $37^{\circ} \mathrm{C}$ and ligated $\mathrm{O} / \mathrm{N}$ at $4^{\circ} \mathrm{C}$ (T4 DNA ligase kit, Promega). PCR

223 was performed on the circularized DNA with primers located in the VPl (14)/ $g f p$ (3), for lpFull

224 and lpVP clones and in right ITR (11)/ $g f p$ (3) for lpNS clones lacking $V P$ sequences. PCR

225 products were run on a 0,8\% agarose gel, purified (NucleoSpin Extract II kit, Macherey-Nagel)

226 and sent for sequencing to the service provider (Genome express; see Table 1 and Figure 1 for

227 primers names, sequences and positions)

228 For walk PCR assays, genomic DNA from GFP+ clones was digested with either SspI, HpaI or

$229 D r a \mathrm{I}$ (several restriction sites in the viral sequence) or $A v a \mathrm{I}$ or EcoRV (non-cutter enzymes). A

230 specific double stranded adaptor with cohesive ends ADPR1/ADPR2 was allowed to hybridize

231 before ligation $\mathrm{O} / \mathrm{N}$ at $37^{\circ} \mathrm{C}$ (T4 DNA ligase kit, Promega) at each extremity of the previously

232 restricted DNA fragments. Then, nested PCRs were performed according to (Sallaud et al. 2003).

233 A set of nested primers located in the ITR sequence was designed $(7,8,9,10,12$ and 13) and

234 two nested primers were selected in the adaptor sequence (AP1, AP2). Each adaptor-ligated

235 fragment was submitted to a series of primary and nested amplifications. EcoRV or AvaI

236 restricted genomic fragments were submitted to ligation and amplification as described above.

237 For walk PCR analysis, 2 overlapping primers located in the VP1 sequence (14 and 15) or in the

$238 g f p(3$ and 16$)$ or in the $N S-3 / \mathrm{UTR}(17,18)$, were used to combine with AP1 and AP2 primers.

239 PCR products were purified and sent for sequencing as above.

Data mining

242 
243 Raw sequences from the amplified fragments were compared to each other, assembled using Cap

2443 (http://doua.prabi.fr/software/cap3) when necessary and submitted for comparison to public 245 databanks

246 - NCBI (http://www.ncbi.nlm.nih.gov/BLAST/) (Altschul et al. 1997),

247 - SPODOBASE (http://bioweb.ensam.inra.fr/spodobase/) and

248 - Lepido DB (http://bipaa.genouest.org/blast/sfru/\#)

249 and aligned against the JcDV, isolate Oxford (GenBank: KC883978.1) using the Megablast

250 conditions for viral sequences and the blastn conditions for the genomic ones. Only the results

251 obtained with an expected value $>10 \mathrm{e} 5$ are taken into consideration.

252

253

254

\section{Results and Discussion}

\section{JcDV-based linear vectors drive stable expression of GFP in $S f^{9}$ cell lines.} positive controls for transfection and GFP expression in $S f 9$ cells. The same plasmids were properly restricted to generate linear molecules encompassing different regions of the viral sequences and the green fluorescent protein $(g f p)$ as a marker gene (Figure 1).

After transfection, expression and accumulation of GFP were monitored under microscopic examination up to 6 days post-transfection (p.t.) then the percentage of GFP positive cells

$262(\mathrm{GFP}+)$ was estimated by visual counting of three different fields ( $\sim 100$ cells).

263 An unrelated control, devoid of JcDV sequences, consisted of plasmid A3GFP which contains

264 the $g f p$ under the control of late actin A3 ubiquitous promoter of Bombyx mori. Transfection of

265 both circular and linearized A3GFP molecules gave rise to a small, rapidly decreasing number of

266 fluorescent cells which was undetectable 1 day p.t.. Although GFP + cells appeared 48 h p.t. using 
267 circular plasmids, their relative number decreased along with time in agreement with previous

268 observations (Bossin et al. 2003). Surprisingly, for most linearized molecules, appearance of

269 GFP+ cells showed a delay before reaching at 6 d. p.t. percentages equivalent to those obtained

270 with circular molecules.

271 Complete deletion of both right- and left ITRs (p9 and p93 ITR respectively, MspA1L) gave rise

272 to rare GFP positive cells which persisted after one month in culture. The resulting expression of

273 GFP can be related to the integration of transfected molecules in a transcribed genomic region.

274 When pFull, pVP and pNS were restricted with $C l a \mathrm{I}+A f l \mathrm{II}$ the GFP + cell number decreased

275 dramatically. Since the ClaI cutting site, located in the pBR322 backbone, is used to generate

276 every linear molecule, this effect is probably due to the AflII cutting site which was brought

277 along with the $g f p$ gene during the construction of plasmids. Restriction with AflII deleted the

278 polyadenylation signals (poly-A) which belong to both ORF1 and ORF2/ORF3 in the ambisense

279 organization of JcDV (Dumas et al. 1992; Shirk et al. 2007) and are present in all three

280 constructs. This result is in agreement with the pivotal role of Polycomb Response Elements in

281 this region, as described by Shirk et al. (Shirk et al. 2007).

282 We subsequently chose three linear molecules allowing high transformation efficiency, for

283 further comparison with the corresponding circular plasmids.

284 pFull as well as pVP, were digested with ClaI $+P v u I I$ which deleted the pBR322 plasmid

285 backbone. lpFull expresses either NS proteins and VP- GFP proteins; lpVP exhibits a deletion

286 within NS sequences.

287 pNS was linearized with $C l a \mathrm{I}+X c m \mathrm{I}$ to obtain the lpNS encompassing the p9 ITR, $g f p$ and the

$288 N S$ sequences, but not the $V P$ ones. Noticeably, deletion of the p93 ITR $(C l a \mathrm{I}+X c m \mathrm{I}$ restrictions $)$

289 seemed not to affect the percentage of cells in which GFP accumulates. XcmI cuts a few 
290 nucleotides upstream the p93 TATA box and still allows expression of ORF2 ORF3 and ORF4

291 (see below).

292 In each pair of linear molecules and circular corresponding ones, the $g f p$ marker gene is

293 expressed, either as a VP-GFP fusion protein ( $\mathrm{pFull,} \mathrm{lpFull;} \mathrm{pVP}, \mathrm{lpVP}$ ) or under the direct

294 control of the p9 capsid protein promoter (pNS, lpNS) (Figure 1).

$295 S f 9$ cells were transfected in parallel with $\mathrm{pFull} / \mathrm{lpFull,} \mathrm{pVP} / \mathrm{lpVP}$ and $\mathrm{pNS} / \mathrm{lpNS}$. The

296 percentage of GFP-fluorescent cells was followed as a function of time p.t.. The results, shown

297 in Figure 2, of three to six independent experiments, allowed the establishment of linear

298 regression profiles of the GFP + cells percentages, at 3, 6, 10, 18. and 30 d. p.t.. All linear

299 constructs gave significant GFP expression starting 6 days p.t.. Transfection of lpFull gave rise

300 to an increasing number of GFP+ cells over the next 20 days to finally reach, at 30 days p.t., a

$30110 \%$ plateau. lpVP transfection gave rise to an increasing number of GFP+ cells reaching $11 \%$ at

30230 days p.t.. The lpNS construct allows the obtention of $4 \% \mathrm{GFP}+$ cells at 30 days p.t.. As

303 expected, VP-GFP expression was visible as a bright punctate staining in the nucleus of lpFull

304 and lpVP transfected cells (Figure 3A) although pNS circular and linear molecules gave rise to a

305 cell widespread GFP expression (Figure 3B). A scheme of individual cell populations obtained

306 after three cloning rounds is shown in Figure 3C.

307

308 Along with cellular divisions, the percentage of GFP-positive cells increased in cells transfected

309 with linear molecules to reach, 30 days post-transfection, an amount 3 to 4 times higher than in

310 cells transfected with circular constructs. It could be hypothesized that early integration events

311 are "stabilized" along with time, meaning that the $g f p$ expression becomes more efficient when

312 the $\mathrm{p} 9$ promoter is surrounded with a favorable molecular environment, for instance after 
313 integration in the chromosomal DNA of the host cell. It is also possible that the p9 promoter

314 activity is regulated along time after integration. The latter possibility is further explored below.

315 Stable GFP-expressing cell clones from both circular and linear molecules transfection were

316 obtained, but only lpFull, lpVP and lpNS transfected cells were used to generate sub-clones

317 derived from a single transfected cell. It is to be noted that along with the cloning processes, GFP

318 expression decline was observed in $10 \%$ of clones due to $g f p$ gene loss as revealed by PCR (not

319 shown). From the rapidly growing cloned populations which were retained for further studies, all

320 exhibited a sustained expression of GFP and were evaluated circa $90 \%$ GFP+ 12 months after

321 cloning (FACS measurement, not shown).

322

$323 \mathrm{JcDV}$ sequences drive integration of vectorized DNA sequences in $S f \boldsymbol{t}$ transfected cells 324

325 To investigate the presence of episomal forms of transfected linear JcDV DNA-based molecules, 326 low- molecular weight DNA from several stable cell clones (lpFull-3f2, lpFull-4a1, lpNS-6f1,

327 lpNS-6f2 lpVP-9f3 and lpVP-9f4) was analyzed by Southern blotting (Figure 4A). No signal was

328 detected when probing with a DIG-labeled linearized JcDV probe suggesting that episomal

329 forms were not detected in the tested clones nor remnant unintegrated linear molecules persisted 330 in the clones.

331

332 To check for integration events, DNA extracted from sub-cloned cell populations, were subjected 333 to Southern Blot analysis (Figure 4B). Genomic DNA was obtained, digested with either AvaI, or $334 A v a \mathrm{I}$ and $H p a \mathrm{I}$, the latter cutting twice within lpFull and lpVP transgene sequences and once in 
335 lpNS molecules (Ava I does not cut within the transgene sequences, see Figure 1). Restricted

336 DNA was hybridized with a full-length ${ }^{32} \mathrm{P}$-labelled JcDV probe.

337 lpFull clones (lpFull-3f2, lpFull-4a1) DNA, digested with AvaI and hybridized to the probe,

338 showed a single band at $12 \mathrm{kbp}$ and $11 \mathrm{kbp}$ respectively, larger than the $7.5 \mathrm{kbp}$ lpFull

339 transfected construct. Integration events in clones $1 p F u l l-3 \mathrm{f} 2$ and $1 \mathrm{pFull}-4 \mathrm{a} 1$ thus occurred at a

340 single but different site in each clone. After double-restriction with AvaI and HpaI, one smaller

341 band is generated from the DNA of either lpFull-3f2 (5.5 kbp) or lpFull-4a1 clone (7 kbp). In the

342 latter restriction, each of both obtained bands is larger than the $3 \mathrm{kbp}$ restricted lpFull transgene

343 sequence suggesting different integration sites in the 2 clones. These data suggest that lpFull

344 sequence integration into lepidopteran cell line $S f 9$ was systematically associated with

345 rearrangements.

346 DNA from the lpVP-9f3 clone (lacking NS genes), restricted with AvaI and Southern-blotted,

347 showed two large bands at $13 \mathrm{kbp}$ and $15 \mathrm{kbp}$ larger than the $6.7 \mathrm{kbp}$ lpVP transfected DNA

348 suggesting more than one integration site. The analysis of lpVP-9f3 clone after restriction with

$349 A v a \mathrm{I}$ and $\mathrm{HpaI}$, shows at least 6 bands at 2.6, 2.8, 5.0, 6.0, 9.0 and $11 \mathrm{kbp}$ smaller or larger than

350 the $3 \mathrm{kbp}$ restricted lpVP transgene sequences. Once again, this indicates that the transfected

351 linear molecules underwent drastic modifications during or after integration in the recipient cell

352 genome. Altogether, the presence of several bands suggests that viral sequences are integrated at 353 different sites into $S f 9$ genome.

354 Consistent with previous observations after transfection of circular plasmid molecules (Bossin et

355 al. 2003), lpFull, which is supposed to retain the capacity of coding NS proteins, gave rise to an

356 apparent small number of integrated molecules. This could be interpreted as a single integration

357 event whereas the analysis of clones obtained after lpVP transfection (modified NS genes) 
358 evoked possible multiple integration sites. We could not confirm concatemeric integration

359 (Bossin et al. 2003).

360 Hybridization of the lpNS-6f2 clone DNA, after digestion with $A v a \mathrm{I}$, revealed four bands

361 estimated larger than $15 \mathrm{kbp}$ and, at least, two additional bands between 10 and $15 \mathrm{kbp}$, which

362 are much larger than the $4.1 \mathrm{kbp}$ of the linear lpNS transfected sequence. It is to be noted that the

363 hybridization signal is much more intense than that observed with lpFull- and lpVP clones, for

364 the same amount of total DNA. This could suggest that more integration events occurred when

365 using lpNS molecules for transfection.

366 After digestion with $A v a \mathrm{I}$ and $H p a \mathrm{I}$, lpNS-6f2 hybridization profile shows a $2.6 \mathrm{kbp}$ band and 10

367 additional bands ranging from $2.2 \mathrm{kbp}$ to $12 \mathrm{kbp}$. The revealed bands are all larger than the $2 \mathrm{kbp}$

368 and $3 \mathrm{kbp}$ lpNS restricted transfected sequences. Linear viral sequences also could probably be

369 heavily rearranged after integration in numerous different sites.

370 To further investigate the organization of integrated viral sequences into $S f 9$ genome, PCR and

371 RT-PCR amplifications were performed on the DNA extracted from GFP+ cell clones.

372

373 Integrated JcDV-derived sequences are rearranged.

374

375 Primers (Table I) were designed to detect two major viral target regions: the $V P$-gfp and the $g f p$ -

$376 N S$ sequences (Figure 1). Additional primers (1', 4; cf. Figure 1) were used to amplify a larger

377 DNA fragment between the $\mathrm{p} 9$ ITR and the $N S$ region.

378 
379 In order to assess the presence of $N S$ and $V P$ sequences in transfected clones, DNA from a

380 selection of representative clones for each transfection was subjected to PCR analysis. The $3 \mathrm{kbp}$

$381 V P$-gfp $(1,2)$ region was successfully amplified from the cellular DNA of all lpFull

382 (lpFull-3f2, lpFull-4a1) and lpVP (lpVP-9f3, lpVP-9f4) subclones, thus demonstrating that at

383 least one copy of this region remains unaffected after integration (Figure 5A). However, several

384 unexpected amplified bands indicate that rearranged copies of this large molecular region are

385 also present within the integrated JcDV-derived sequences in lpVP clones.

386 Using primers 1' and 4, the expected p9 ITR-NS $3.4 \mathrm{kbp}$ fragment is amplified from clone lpNS-

$3876 f 2$ DNA only (Figure 5B). lpFull-3f2 and lpVP-9f3 DNA did not support the amplification of

388 the expected $6 \mathrm{kbp}$ and $5.1 \mathrm{kbp}$ fragments respectively (Figure 5B). Since lpVP-9f3 and lpFull-

$3893 \mathrm{f} 2 \mathrm{DNA}$ gave rise to the amplification of $3.2 \mathrm{kbp}$ and $3 \mathrm{kbp}$ fragments respectively, the target

390 DNA is likely to be affected by large deletions.

391 This was confirmed since $N S$-gfp region amplification (primers 3/4, Figure 1) generated smaller

392 bands than expected from the cellular DNA of $1 p F u l l-3 f 2$ and $1 p F u l l-4 a 1$ clones (expected band:

$3933.7 \mathrm{kbp}$, amplified: $0.4 \mathrm{kbp}$, ) and in lpVP-9f3 and lpVP-9f4 clones (expected band: $3 \mathrm{kbp}$,

394 amplified: $1 \mathrm{kbp}$,) Furthermore, in lpNS-6f1 and lpNS-6f2 clones, the expected $2.6 \mathrm{kbp}$ band was

395 properly amplified as well as an additional band at $2 \mathrm{kbp}$ (Figure 5C). These data show that at

396 least one complete NS-gfp sequence is present within the genome of the lpNS transfected clones,

397 whereas lpFull and lpVP DNAs do not support PCR amplification of this region.

398 Altogether, these results suggest that all lpFull, lpNS and lpVP clones, which were recovered and

399 amplified, contain at least one copy each of a $V P$ - or $\mathrm{p} 9-g f p$ sequence stably integrated within the

$400 S f 9$ genome whereas the repeated failure to amplify $N S$ gene sequences from lpFull and lpVP

401 clones indicate that major modifications, probably deletions, has occurred in this region along 
402 with the integration and/or cell cloning process. Only in lpNS clones one copy of the p93 ITR-

403 NS region remained intact after integration.

404 In order to verify that the full NS copy could be functionally expressed, total mRNA was

405 extracted from all stable clones and tested by RT-PCR for VP-GFP fusion transcripts as well as 406 for NS transcription (Figure 5D). Even if the RT kit involves a DNAse step, the RNA samples

407 were verified DNA free according to direct PCR (not shown).

408 As expected, VP-GFP fusion mRNA, was successfully retrotranscribed then PCR-amplified in 409 all lpFull, lpVP and lpNS clones (data not shown).

410 Only the mRNA extracted from lpNS-6f2 cells and subjected to RT-PCR amplification of the

411 UTR-NS-1 region, gave rise to amplification of both the expected $400 \mathrm{bp}$ (spliced form; (Abd-

412 Alla et al. 2004) and $1080 \mathrm{bp}$ (unspliced form) bands, indicating that the $2.4 \mathrm{~kb}$ and $1.7 \mathrm{~kb}$ NS

413 transcripts can be expressed in lpNS clones. An additional 800 bp band suggests that an

414 unidentified mRNA transcript is also expressed from one of the numerous integrated JcDV-based

415 sequences after transfection of $S f 9$ cells with lpNS molecules.

416 Attempts to amplify the 400bp and/or the 1080bp band failed with cDNA obtained from lpFull

417 and lpVP clones (Figure 5D).

418

419 Rearranged viral regions are interspersed with non-viral sequences in transfected $S \boldsymbol{f} \boldsymbol{9}$ cells. 420

421 In order to identify and characterize more precisely the rearrangement pattern as well as some of

422 the junctions between integrated virus-based molecules and cellular Sf9 DNA, stable fluorescent

423 clones resulting from $1 \mathrm{pF}$ ull, $\mathrm{lpNS}$ and $\mathrm{lpVP}$ transfections were analyzed using reverse PCR

424 (Ochman et al. 1993) and walk-PCR (Sallaud et al. 2003). Each DNA sequence obtained after 
425 reverse- or walk-PCR was verified, by direct amplification of the cellular DNA extracted from

426 JcDV-transfected clones, to generate a properly sized band (not shown). The raw sequences are

427 presented in a fasta format in supplemental material and Figure 6 A, B, C summarize the global

428 repartition of "scrambled" viral integrated sequences according to their respective positions in

429 transfected constructs.

430 Briefly, the isolation of sequences containing mainly rearranged viral sequences is the signature

431 of a dense recombination activity of cellular origin.

432 We repeatedly found, and verified, roughly the same viral rearrangement in each of the analyzed

433 lpFull subclones (Figure 6A) bringing together a NS-1/NS-2 fragment and a VP4 fragment,

434 otherwise distant of $\sim 700$ nucleotides in the originally transfected molecule, and placed in

435 opposite orientations. Noteworthy, the considered VP4 fragment lies in the 3' VP coding

436 sequence which was displaced from the $V P$ gene by the $g f p$ insertion. Both went close to the p9

437 ITR. We also found molecules joining the same $N S$ sequence with the same ITR nucleotides,

438 without $V P$ sequences. The integration situation thus seems to be rather simple in lpFull clones

439 since only one rearrangement, was characterized from the different clones tested which are

440 unlikely to be issued from the same transfected cell, even if we cannot exclude this possibility.

441 Two non-viral sequences were identified interspersed with viral sequences (see below)

442 Five different lpVP clones and sub-clones were analyzed by walk-PCR and/or by reverse PCR

443 (Figure 6B). Two different sequences, shared by all the lpVP subclones and two clone-specific

444 rearrangements were analyzed. All these sequences show the involvement of ITRs sequence

445 fragments rearranged with $N S$ and/or $V P$ sequences fragments issued undoubtedly from the

446 transfected linear vector. Among the few non-viral DNA sequences interspersed within the

447 rearrangements, two were large enough to deserve identification (see below). 
448 lpNS integrants are diverse in number, size and composition (Figure 6C). They involve either

449 ITR or ITR/NS sequences. Non-viral sequences, too short to be identified, alternate with vector-

450 derived sequences, viral or not ( $g f p, \mathrm{pBR} 322$, other).

451

\section{Non-viral sequences are interspersed with viral ones in the rearrangements}

453

454 The recent publication of two Spodoptera frugiperda genomes (Gouin et al. 2017) enriched the

455 data base with pertinent sequences. All the non-viral sequences were compared to each other and 456 to online databases NCBI (http://www.ncbi.nlm.nih.gov/BLAST/) (Altschul et al. 1997), ,

457 SPODOBASE (http://bioweb.ensam.inra.fr/spodobase/) and Lepido DB

458 (http://bipaa.genouest.org/blast/sfru/\#) with an expected value $>10 \mathrm{e} 5$.

460 Figure 6 A to $\mathrm{C}$ schematizes the location of cleaned viral sequences along the sequences of the 461 transfected linear molecules, $1 \mathrm{pFull}, \mathrm{lpVP}$ and $\mathrm{lpNS}$ respectively. No non-viral sequence (or not 462 present in the transfected molecules) was identified in the lpNS rearrangements. Non-viral and 463 unidentified sequences were found in the lpVP and lpFull rearrangements.

464 The sequence identified as "lpVP_1" " as well as the sequence "lpVP_1/1" in supplemental 465 material matched with numerous genomic sequences, best matches being with "Spodoptera 466 frugiperda 41I04_SfBAC" [id : FP3404412.1] and "Spodoptera frugiperda 75E05_SfBAC" [id: 467 FO681368. 1].

468 The sequences identified as "lpFull_AP2/6a", "lpFull_AP2/1a" and "lpFull_12/1" in the 469 supplemental material match mainly with the "Spodoptera frugiperda sequence from BAC clone 470 68E14” ([GenBank : FO681381.1]. Since these viral and cellular sequences are heavily modified 
471 and interspersed with unidentified small DNA sequences, we preferred to schematize their

472 location in figure 6.

473 Last, the sequence identified as "lpFull_AP2/16a" in the supplemental material matches mainly

474 with the "Spodoptera frugiperda cell-line Sf9 ribosomal genes its1 and its2 [id: GQ478352.1].

475 Note that in this case 63 nts of genomic sequence (1326-1389) overlap with 26 nts of viral

476 sequences from the ITRs $(2-28,5904-5930)$, we cannot claim that it is a true junction.

477 Sequences "IpFull_AP2/7" and "lpFull_AP2/6b" exhibit also genomic sequences but the viral

478 moiety of these sequences is too tiny to deserve mention. The BACs have been extensively

479 described (d'Alencon et al. 2004; d'Alencon et al. 2010), and, according to their organization, the

480 sequences evoked before could pertain to highly repetitive, non-coding and intergenic regions.

481 Using a preliminary version of transposable elements (TE) annotation of the " $S f$ corn strain

482 genome assembly" (Gouin et al. 2017), we found that, indeed, all the characterized flanking

483 sequences are located in intergenic regions and/or different TE sequences which remain to be

484 identified. Incidentally, the previously described flanking sequences of the circular vectors

485 (Bossin et al. 2003) were also found located in intergenic and TE regions. However Sf genomic

486 and transcriptomic data are currently insufficient to sustain the hypothesis of genomic

487 rearrangements induced by JcDV integration vs. genomic sequences with identities to viral

488 sequences as already evoked (Liu et al. 2011), whatever the cause.

489

490 NS proteins do not transactivate the p9 promoter

491

492 Considering only the results obtained with lpFull and lpVP clones, we seem to corroborate

493 previous conclusions, i.e. in the presence of $N S$ genes, integration of JcDV-derived sequences 
494 integrate within the host-cell genome at a low, probably single copy number although deletion of

495 NS genes allows multiple copies integration, even if we cannot provide evidence of concatemers

496 generation and integration from linear pVP molecules. However, as evoked in the same work and

497 as reported for non-structural proteins from Parvovirinae (Batchu et al. 2001; Daeffler et al.

498 2003), a maintained expression of JcDV NS proteins may be harmfull for the host cell and

499 interfere with the cell cycle. Thus, it is not surprising to recover only cell clones having lost the

500 capacity of NS expression after JcDV-based sequences integration. This is confirmed by the

501 extensive rearrangements of NS coding sequences which rendered their expression unlikely.

502 Moreover, a retrospective PCR amplification indicates that NS gene was already undetectable 6

503 days p.t in lpFull-transfected cells (not shown). Similarly, cells transfected with pNS and lpNs

504 have allowed the isolation of only some GFP + clones (Figure 2). However, in the DNA

505 extracted from lpNS cell clones, numerous rearranged viral sequences interspersed with DNA

506 fragments from a different origin, are accompanied with a sustained expression of NS mRNA.

507 This could be explained by an expression of the NS genes low enough not to perturb the cell

508 cycle. Actually, the Xcm I restriction used to generate lpNS cuts the viral sequence between the

509 p93 TATA box and the regulatory sequences (Dumas et al. 1992) and this could account a

510 reduced expression of p93 driven mRNA. Our results are concordant with recently published

511 data showing that numerous genomes are interspersed with parvovirus-related sequences (PRDs)

512 (Liu et al. 2011) or endogenous viral elements (EVEs) (Katzourakis \& Gifford 2010; Theze et al.

513 2014) often fragmented/rearranged.

514 Nevertheless, we were unable to explain two results: i) the percentage of GFP expressing cells

515 increases with time in all the clones (Figure 2), ii) lpNS transformed cells seem to express GFP 
516 less stably and less efficiently than lpVP and lpFull transformed ones (Figure 3B). We thus

517 explored in vitro the regulatory activities of NS proteins on the p9 promoter.

518

519 Three plasmid vectors were built to express NS-1, NS-2 and NS-3, respectively. A reporter

520 plasmid was adapted to place the expression of $L u c$ under the control of $\mathrm{p} 9$ promoter and IPLB-

521 Ld652 permissive cells were co-transfected to perform a "luciferase" assay matched against the

522 Renilla luciferase expression. Figure 7 clearly indicates that NS-1 expression does not

523 significantly affect $\mathrm{p} 9$ activity even if we cannot ascertain that a functional amount of NS1 is

524 produced. This is not completely unexpected since JcDV NS-1 seems to lack the COOH-

525 terminus transactivation-associated region (Legendre \& Rommelaere 1994; Nuesch 2006; Yang

526 et al. 2006). Transactivation of the $\mathrm{p} 9$ promoter is neither devoted to NS-2 or NS-3 which on the

527 contrary down-regulate it at $96 \mathrm{~h}$. In addition, it is clear that the "basal" activity of the p9

528 promoter augments along with time, in vitro also. So, it is no more surprising that integration of

529 linear molecules expressing GFP under the control of the p9 promoter is accompanied with a

530 growing number of "green" cells, probably due to the growing number of cells which become

531 detectable along with time. Also, the limited number of GFP expressing cells, even 30 days post

532 transfection of $1 \mathrm{pNS}$ linear vector could be explained by the retained capacity of these cells to

533 express the NS genes.

534

535 In vivo, injection of JcDV-derived plasmids in insect syncitial embryo gives rise to a somatic

536 transformation of some cells throughout the larval stages (Royer et al. 2001). However, the

537 modification does not cross the barrier of the germ cells. It remains to go further on the way of

538 insect transformation, using linear JcDV-derived molecules equipped with a right ITR to 
539 integrate efficiently, a strong promoter, JcDV p9 being a good candidate, and an insect-

540 compatible poyadenylation signal. Non-structural protein(s) expression, although probably useful

541 for original single integration profile, are probably involved also in the rearrangement of both

542 viral and cellular genomes. The Dependoparvovirus adeno-associated virus type 2 (AAV2)

543 genome is site specifically integrated after interaction of Rep (NS) proteins and cellular proteins

544 mainly involved in DNA repair (Nash et al. 2009), including nonhomologous end joining

545 (NHEJ) proteins (Daya et al. 2009). Although the JcDV NS1 protein, as AAV2 Rep protein,

546 recognizes and binds to a specific sequence of viral DNA (Ding et al. 2002), it does not seem

547 capable of directing site-specifically the integration of the viral genome within the host genome.

548 Cellular proteins could therefore be the major players in this integration. The fact that the

549 flanking sequences are identified as "noncoding" may reflect spontaneous selection of cell clones 550 least affected by the integration.

551

552

553

554

555

556

557

558

559

560

561

562

\section{Conclusions}

We investigated the status of JcDV-based linear DNA molecules after transfection in nonpermissive $S f 9$ cells. Molecules harboring either complete JcDV sequences or ITRs and $v p$, i.e. the linear equivalent to the plasmids reported in [8] or only p9-ITR and $n s$, the $g f p$ being directly under the control of the p9 promoter, lead to GFP stable expression in transfected cells. However, JcDV sequences integration was systematically associated with major rearrangements (scrambling) even in the case of a possibly single integration event after transfection with complete JcDV-based molecule. Some genomic host-sequences were caught in the rearrangements and remain mostly unidentified even if some correspond to non-coding and repeated or transposable sequences. The lower number of cells expressing GFP in cells harboring 
563 a possible continuous expression of NS proteins as well as the obvious increase along with time

564 of the number of GFP+ cells were intriguing. A luciferase assay of the NS-mediated regulation

565 of the p9 promoter activity revealed that on the contrary to other Parvoviridae, NS-1 protein

566 from JcDV seems not to transactivate the promoter driving the expression of structural proteins.

567 In addition, NS-2 and NS-3 proteins down-regulate the p9 promoter late after transfection.

568 Altogether, it is possible to use JcDV-derived linear sequences, provided they harbor at least one

569 ITR and poly-A signals, to direct the random integration of a reporter gene. The presence of $n s$

570 genes could be facultative since integration seems mainly due to cellular factors.

571

572

573

574

575

576

577

578

579

580

581

582

583

584

585

586

587

588

589

590

\section{Acknowledgments}

The authors are indebted to M. Bergoin for the kind gift of original JcDV-based plasmids. J.

Vlak is acknowledged for the gift of the Renilla luciferase vector and M. Ravallec for skilful assistance with microscopy. D. Mieulet is gratefully acknowledged for help with walk-PCR technique. Micheline Durand is acknowledged for her assistance during this study. FrançoiseXavière Jousset and Philippe Fournier are acknowledged for their guidance and useful critics.

We also want to thank the referees for their helpful comments and suggestions.

Abd-Alla A, Jousset FX, Li Y, Fediere G, Cousserans F, and Bergoin M. 2004. NS-3 protein of the Junonia coenia densovirus is essential for viral DNA replication in an Ld 652 cell line and Spodoptera littoralis larvae. J Virol 78:790-797.

Afanasiev B, and Carlson J. 2000. Densovirinae as gene transfer vehicles. In: Faisst S, and Rommelaere J, eds. Parvoviruses, 33-58.

Altschul SF, Madden TL, Schaffer AA, Zhang J, Zhang Z, Miller W, and Lipman DJ. 1997. Gapped BLAST and PSI-BLAST: a new generation of protein database search programs. Nucleic Acids Res 25:3389-3402. 
591

592

593

594

595

596

597

598

599

600

601

602

603

604

605

606

607

608

609

610

611

612

613

614

615

616

617

618

619

620

621

622

623

624

625

626

627

628

629

630

631

632

633

634

635

636

Batchu RB, Shammas MA, Wang JY, and Munshi NC. 2001. Dual level inhibition of E2F-1 activity by adeno-associated virus Rep78. J Biol Chem 276:24315-24322.

Belloncik S. 1990. Potential use of densonucleosis virus as biological control agents of insect pests. In: Tijssen P, ed. Handbook of Parvoviruses. Boca Raton. Florida: CRC Press Inc, 29-39.

Bergoin M, and Tijssen P. 1998. Biological and molecular properties of densoviruses and their use in protein expression and biological control. In The insect viruses, pp. 141-169. Edited by L.K. Miller and L. A. Ball. Plenum Press. New York.

Bossin H, Fournier P, Royer C, Barry P, Cerutti P, Gimenez S, Couble P, and Bergoin M. 2003. Junonia coenia densovirus-based vectors for stable transgene expression in Sf9 cells: influence of the densovirus sequences on genomic integration. $J$ Virol 77:11060-11071.

Bossin H, Furlong RB, Gillett JL, Bergoin M, and Shirk PD. 2007. Somatic transformation efficiencies and expression patterns using the JcDNV and piggyBac transposon gene vectors in insects. Insect Mol Biol 16:37-47. 10.1111/j.1365-2583.2006.00693.x

Corsini J, Tal J, and Winocour E. 1997. Directed integration of minute virus of mice DNA into episomes. J Virol 71:9008-9015.

d'Alencon E, Piffanelli P, Volkoff AN, Sabau X, Gimenez S, Rocher J, Cerutti P, and Fournier P. 2004. A genomic BAC library and a new BAC-GFP vector to study the holocentric pest Spodoptera frugiperda. Insect Biochem Mol Biol 34:331-341. 10.1016/j.ibmb.2003.12.004

S0965174803002224 [pii]

d'Alencon E, Sezutsu H, Legeai F, Permal E, Bernard-Samain S, Gimenez S, Gagneur C, Cousserans F, Shimomura M, Brun-Barale A, Flutre T, Couloux A, East P, Gordon K, Mita K, Quesneville H, Fournier P, and Feyereisen R. 2010. Extensive synteny conservation of holocentric chromosomes in Lepidoptera despite high rates of local genome rearrangements. Proc Natl Acad Sci U S A 107:7680-7685.

Daeffler L, Horlein R, Rommelaere J, and Nuesch JP. 2003. Modulation of minute virus of mice cytotoxic activities through site-directed mutagenesis within the NS coding region. $J$ Virol 77:12466-12478.

Daya S, Cortez N, and Berns KI. 2009. Adeno-associated virus site-specific integration is mediated by proteins of the nonhomologous end-joining pathway. $J$ Virol 83:1165511664. 10.1128/JVI.01040-09

Ding C, Urabe M, Bergoin M, and Kotin RM. 2002. Biochemical characterization of Junonia coenia densovirus nonstructural protein NS-1. J Virol 76:338-345.

Dumas B, Jourdan M, Pascaud AM, and Bergoin M. 1992. Complete nucleotide sequence of the cloned infectious genome of Junonia coenia densovirus reveals an organization unique among parvoviruses. Virology 191:202-222.

Fediere G. 2000. Epidemiology and pathology of Densovirinae. In: Faisst S, and Rommelaere J, eds. Parvoviruses, 1-11.

Gouin A, Bretaudeau A, Nam K, Gimenez S, Aury JM, Duvic B, Hilliou F, Durand N, Montagne N, Darboux I, Kuwar S, Chertemps T, Siaussat D, Bretschneider A, Mone Y, Ahn SJ, Hanniger S, Grenet AG, Neunemann D, Maumus F, Luyten I, Labadie K, Xu W, Koutroumpa F, Escoubas JM, Llopis A, Maibeche-Coisne M, Salasc F, Tomar A, Anderson AR, Khan SA, Dumas P, Orsucci M, Guy J, Belser C, Alberti A, Noel B, Couloux A, Mercier J, Nidelet S, Dubois E, Liu NY, Boulogne I, Mirabeau O, Le Goff G, Gordon K, Oakeshott J, Consoli FL, Volkoff AN, Fescemyer HW, Marden JH, Luthe DS,

PeerJ reviewing PDF | (2018:02:23949:1:1:REVIEW 21 Apr 2018) 
637

638

639

640

641

642

643

644

645

646

647

648

649

650

651

652

653

654

655

656

657

658

659

660

661

662

663

664

665

666

667

668

669

670

671

672

673

674

675

676

677

678

679

680

681

Herrero S, Heckel DG, Wincker P, Kergoat GJ, Amselem J, Quesneville H, Groot AT, Jacquin-Joly E, Negre N, Lemaitre C, Legeai F, d'Alencon E, and Fournier P. 2017. Two genomes of highly polyphagous lepidopteran pests (Spodoptera frugiperda, Noctuidae) with different host-plant ranges. Sci Rep 7:11816. 10.1038/s41598-017-10461-4

Gu J, Liu M, Deng Y, Peng H, and Chen X. 2011. Development of an efficient recombinant mosquito densovirus-mediated RNA interference system and its preliminary application in mosquito control. PLoS One 6:e21329.

Hendrie PC, Hirata RK, and Russell DW. 2003. Chromosomal integration and homologous gene targeting by replication-incompetent vectors based on the autonomous parvovirus minute virus of mice. J Virol 77:13136-13145.

Janovitz T, Klein IA, Oliveira T, Mukherjee P, Nussenzweig MC, Sadelain M, and FalckPedersen E. 2013. High-throughput sequencing reveals principles of adeno-associated virus serotype 2 integration. J Virol 87:8559-8568.

Katzourakis A, and Gifford RJ. 2010. Endogenous viral elements in animal genomes. PLoS Genet 6:e1001191.

Legendre D, and Rommelaere J. 1994. Targeting of promoters for trans activation by a carboxyterminal domain of the NS-1 protein of the parvovirus minute virus of mice. $J$ Virol 68:7974-7985.

Liu H, Fu Y, Xie J, Cheng J, Ghabrial SA, Li G, Peng Y, Yi X, and Jiang D. 2011. Widespread endogenization of densoviruses and parvoviruses in animal and human genomes. $J$ Virol 85:9863-9876.

Mange A, Julien E, Prudhomme JC, and Couble P. 1997. A strong inhibitory element downregulates SRE-stimulated transcription of the A3 cytoplasmic actin gene of Bombyx mori. J Mol Biol 265:266-274.

Nalcacioglu R, Marks H, Vlak JM, Demirbag Z, and van Oers MM. 2003. Promoter analysis of the Chilo iridescent virus DNA polymerase and major capsid protein genes. Virology 317:321-329.

Nash K, Chen W, Salganik M, and Muzyczka N. 2009. Identification of cellular proteins that interact with the adeno-associated virus rep protein. $J$ Virol 83:454-469.

Nuesch JP. 2006. Regulation of non-structural protein functions by differential synthesis, modification and trafficking. In: Kerr JR, Cotmore SF, Bloom ME, Linden RM, and Parrish CR, eds. Parvoviruses. London: Hodder Arnold, 275-289.

Ochman H, Ayala FJ, and Hartl DL. 1993. Use of polymerase chain reaction to amplify segments outside boundaries of known sequences. Methods Enzymol 218:309-321.

Royer C, Bossin H, Romane C, Bergoin M, and Couble P. 2001. High amplification of a densovirus-derived vector in larval and adult tissues of Drosophila. Insect Mol Biol 10:275-280.

Sallaud C, Meynard D, van Boxtel J, Gay C, Bes M, Brizard JP, Larmande P, Ortega D, Raynal M, Portefaix M, Ouwerkerk PB, Rueb S, Delseny M, and Guiderdoni E. 2003. Highly efficient production and characterization of T-DNA plants for rice ( Oryza sativa L.) functional genomics. Theor Appl Genet 106:1396-1408.

Sambrook J, Fritsch EF, and Maniatis T. 1989. Molecular Cloning: A Laboratory Manual. Cold Spring Harbor. New York.

Shirk PD, Bossin H, Furlong RB, and Gillett JL. 2007. Regulation of Junonia coenia densovirus P9 promoter expression. Insect Mol Biol 16:623-633. 
682 Tal J, and Attathom T. 1993. Insecticidal potential of the insect parvovirus GmDNV. Arch Insect 683 Biochem Physiol 22:345-356.

684 Theze J, Leclercq S, Moumen B, Cordaux R, and Gilbert C. 2014. Remarkable diversity of 685 endogenous viruses in a crustacean genome. Genome Biol Evol 6:2129-2140.

686 Vaughn JL, Goodwin RH, Tompkins GJ, and McCawley P. 1977. The establishment of two cell 687 lines from the insect Spodoptera frugiperda (Lepidoptera; Noctuidae). In Vitro 13:213688217.

689 Wang Y, Abd-Alla AM, Bossin H, Li Y, and Bergoin M. 2014. Analysis of the transcription 690 strategy of the Junonia coenia densovirus (JcDNV) genome. Virus Res 174:101-107. $691 \quad$ 10.1016/j.virusres.2013.03.008

692 Yang B, Zhang J, Cai D, Li D, Chen W, Jiang H, and Hu Y. 2006. Biochemical characterization 693 of Periplaneta fuliginosa densovirus non-structural protein NS1. Biochem Biophys Res Commun 342:1188-1196.

696

697

Ziegler K, Bui T, Frisque RJ, Grandinetti A, and Nerurkar VR. 2004. A rapid in vitro polyomavirus DNA replication assay. $J$ Virol Methods 122:123-127.

698 


\section{Figure $\mathbf{1}$ (on next page)}

Schematic organization of JCDV-based plasmids used to generate linear sequences for transfection experiments

pBR322 backbone is figured as dotted grey line. JcDV structural proteins (VP) coding sequences are represented by a solid black line; non-structural proteins (NS) genes by a solid grey line. Both share a polyadenylation signal shown as an open ellipse. Open boxes figure the $p 9$ and $p 93$ ITRs, hatched boxes underline the location of $p 9$ and $p 93$ promoters, respectively. GFP coding sequence is figured with a grey box and its 3' SV40-derived polyadenylation signal is shown as a hatched line. Arrows numbered according to Table 1 figure the primers used for PCR-based experiments. Primers used for walk-PCR are represented above; primers 7 to 13 represented only relatively to $p 9$ can also hybridize to p93 DNA sequences when present. Grey-filled arrowheads figure restriction sites used to generate linear molecules from the plasmid constructs. Open arrowheads figure restriction sites used for walk-PCR experiments. Subscript numbers indicate iterated restriction sites. By convention, nucleotide numbers of each linear molecule are accorded to the $5^{\prime} \mathrm{C}$ generated after Clal restriction (AT/CGAT). Restriction enzymes are: A: Afll, C: Clal, D: Dral, H: Hpal, M: MspA1L, S: Sspl, P: PshAl, Pv: Pvull, X: Xcml, respectively. Linear molecules were obtained after restriction of 3 different JCDV-based vectors. Their length is indicated under the name of each plasmid, on the left: (A) pFull encompassing a full-length sequence of JcDV DNA and the GFP marker gene, cloned into pBR322 plasmid. This schematic representation displays all the symbols described above; some of them only are reported in B and C. (B) PVP in comparison to pFull, a frameshift deletion affects the NS region (C) pNS in comparison to pFull, lacks VP genes. The expression of GFP is directly under the control of the p9 promoter. Primers giving rise to specific products after PCR are shown (See Table 1). 

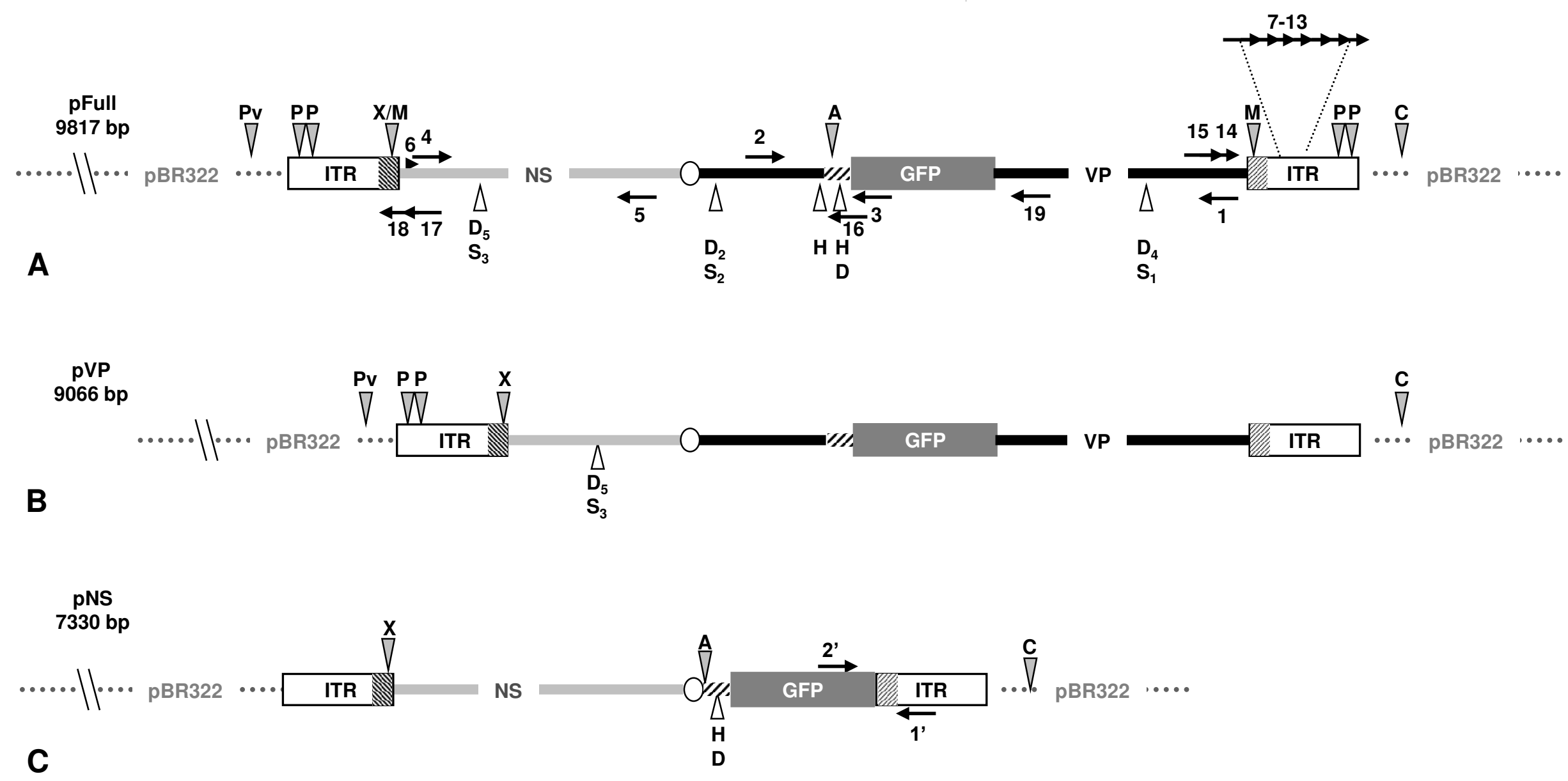


\section{Figure 2 (on next page)}

Relative enrichment of GFP+ cells along with growth of transfected Sf9 cells

Following transfection of Sfg cells using Jet PEI and indicated DNA molecules, GFP expression was measured in cell populations 3 days, $6 \mathrm{~d} ., 10 \mathrm{~d}$., $18 \mathrm{~d}$. and $30 \mathrm{~d}$. post-transfection (p.t.) by flow cytometry. The percentage of GFP+ cells was measured in 3 to 5 independent experiments and the results are reported on each coordinates. Linear regression curves can be drawn which show the evolution of GFP+ cells percentages along time $\left(R^{2}>0.5\right)$. a: non significative, $b: p<0.05, c: p<0.01$ (Wilcoxon rank sum test with continuity correction, $R$ suite). 


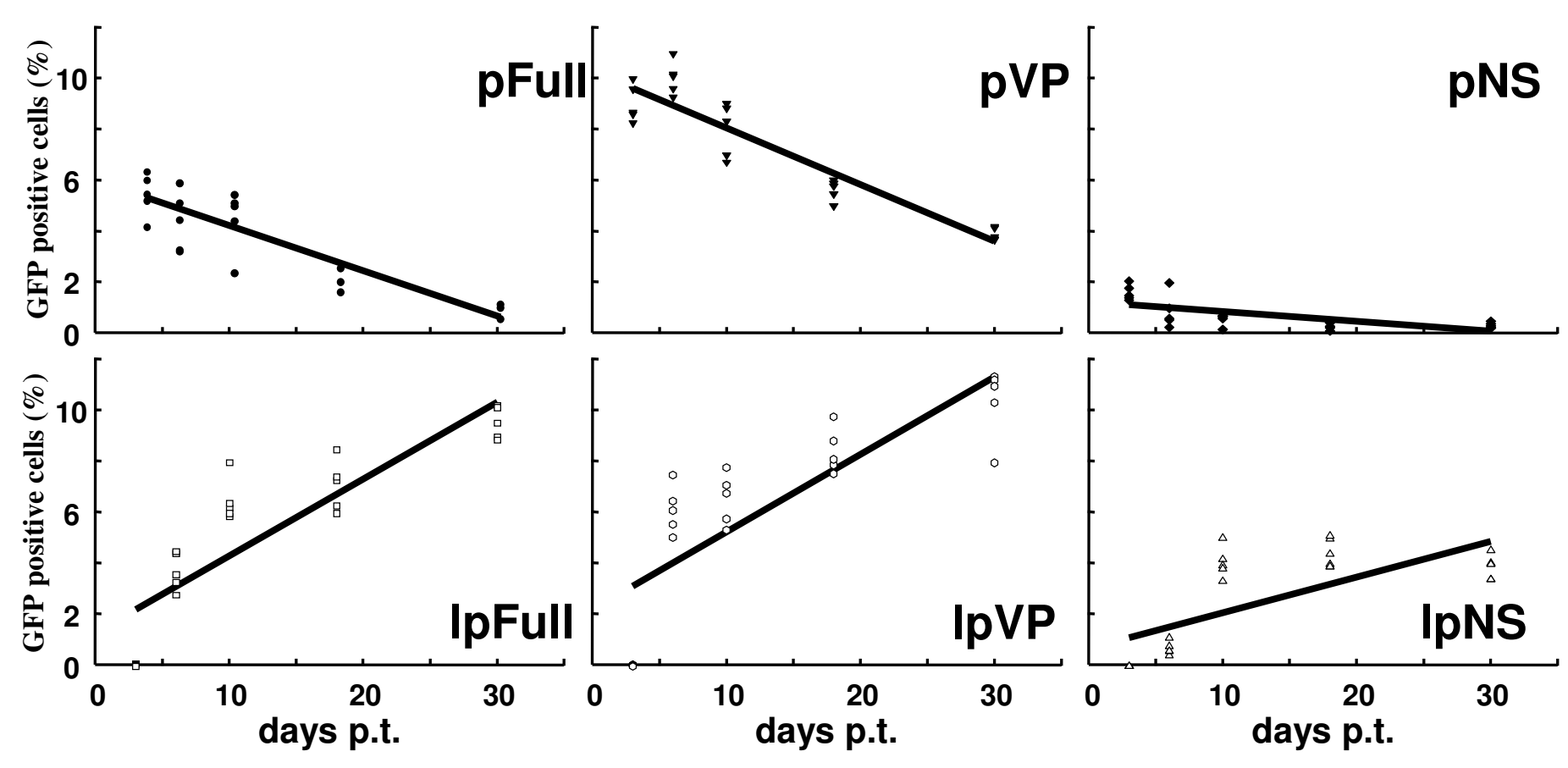




\section{Figure 3}

Cellular clones showing persistent expression of GFP after transfection with JcDV-based linear molecules

(A) Typical clump of cells transfected with IpFull or IpVP and showing mainly nuclear localization of the GFP fluorescence. (B) Widespread cytoplasmic fluorescence in IpNS transfected cells. (C) Isolation scheme of clonal cell populations from clumps exemplified in A and B. Numbers between brackets are the percentage of fluorescent cells in each clone as measured by cytometry. Several stable fluorescent cell clones were recovered and designated IpX-n1Yn2, "I" is for linearized, "pX" for the plasmid origin of the molecule and the combination "n1Yn2" depicts the steps of clonal population isolation.
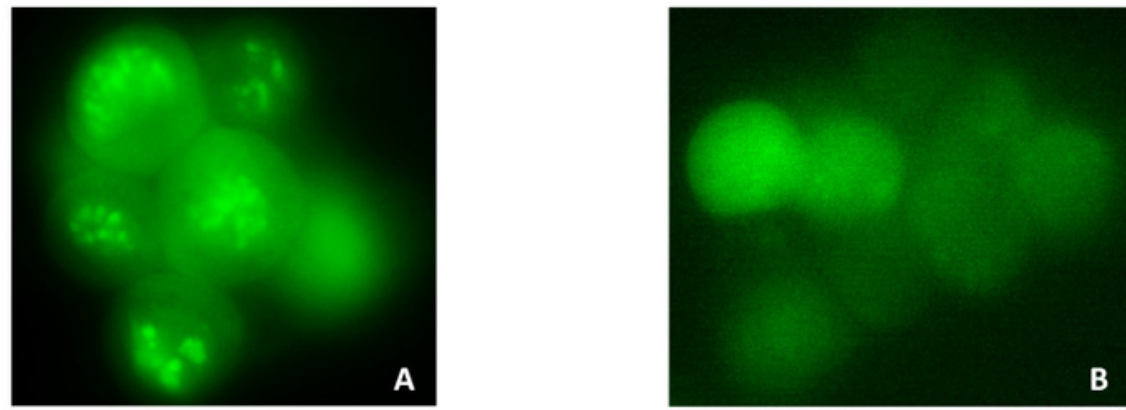

\begin{tabular}{|c|l|l|l|}
\hline C & \multicolumn{1}{|c|}{ IpFull } & \multicolumn{1}{|c|}{ IpVP } & \multicolumn{1}{|c|}{ IpNS } \\
\hline $\begin{array}{c}\text { Cellular clones } \\
\text { recovered 30 days p.t. }\end{array}$ & IpFull (1 to 14) & IpVP (1 to 16) & IpNS (1 to 12) \\
\hline $\begin{array}{c}\text { Cellular clones } \\
\text { recovered 60 days p.t. }\end{array}$ & $\begin{array}{l}\text { IpFull-3b (53,1\%) } \\
\text { IpFull-3f (62,1\%) } \\
\text { IpFull-4a (77,1\%) }\end{array}$ & $\begin{array}{l}\text { IpVP-3f (45,8\%) } \\
\text { IpVP-9f (55,5\%) }\end{array}$ & $\begin{array}{l}\text { IpNS-6f (43,6\%) } \\
\text { IpNS-8f (40,0\%) }\end{array}$ \\
\hline $\begin{array}{c}\text { Cellular clones } \\
\text { recovered 80 days p.t. }\end{array}$ & $\begin{array}{l}\text { IpFull-3b1 (87,0\%) } \\
\text { IpFull-3b2 (84,2\%) } \\
\text { IpFull-3f1 (82,3\%) } \\
\text { IpFull-3f2 (92,0\%) } \\
\text { IpFull-4a1 (90,1\%) }\end{array}$ & $\begin{array}{l}\text { IpVP-9f1 (88,2\%) } \\
\text { IpVP-9f2 (91,3\%) } \\
\text { IpVP-9f3 (95,7\%) } \\
\text { IpVP-9f4 (93,8\%) }\end{array}$ & $\begin{array}{l}\text { IpNS-6f1 (53,9\%) } \\
\text { IpNS-6f2 (52,4\%) }\end{array}$ \\
\hline
\end{tabular}




\section{Figure 4}

Integration patterns are dependent on transfected viral sequences

(A) Low molecular weight (LMW) DNA was extracted from two different stable subclones per linear construct and hybridized with a DIG-labelled probe. $\mathrm{pB}, \mathrm{pVP}$ and $\mathrm{pFull}$ represent $\mathrm{pBRJH}$ (Dumas et al. 1992) , pVP and pFull native plasmids, respectively. Sf9h, $\mathrm{pBh}, \mathrm{pVPh}$ and $\mathrm{pHh}$ indicate LMW DNA extracted from mock-transfected, pB, pVP and pFull transfected Sf9 cells, respectively. (B) Genomic DNA was isolated from stable fluorescent cell sub-clones, restricted with either Aval (A) or Aval $+\mathrm{Hpal}(\mathrm{A}+\mathrm{H})$ and separated electrophoretically. Hybridization was performed using a radioactively labeled probe. pFull plasmid and the subsequent linearized IpFull are used as positive control. Sf9 DNA was used as a negative control. 

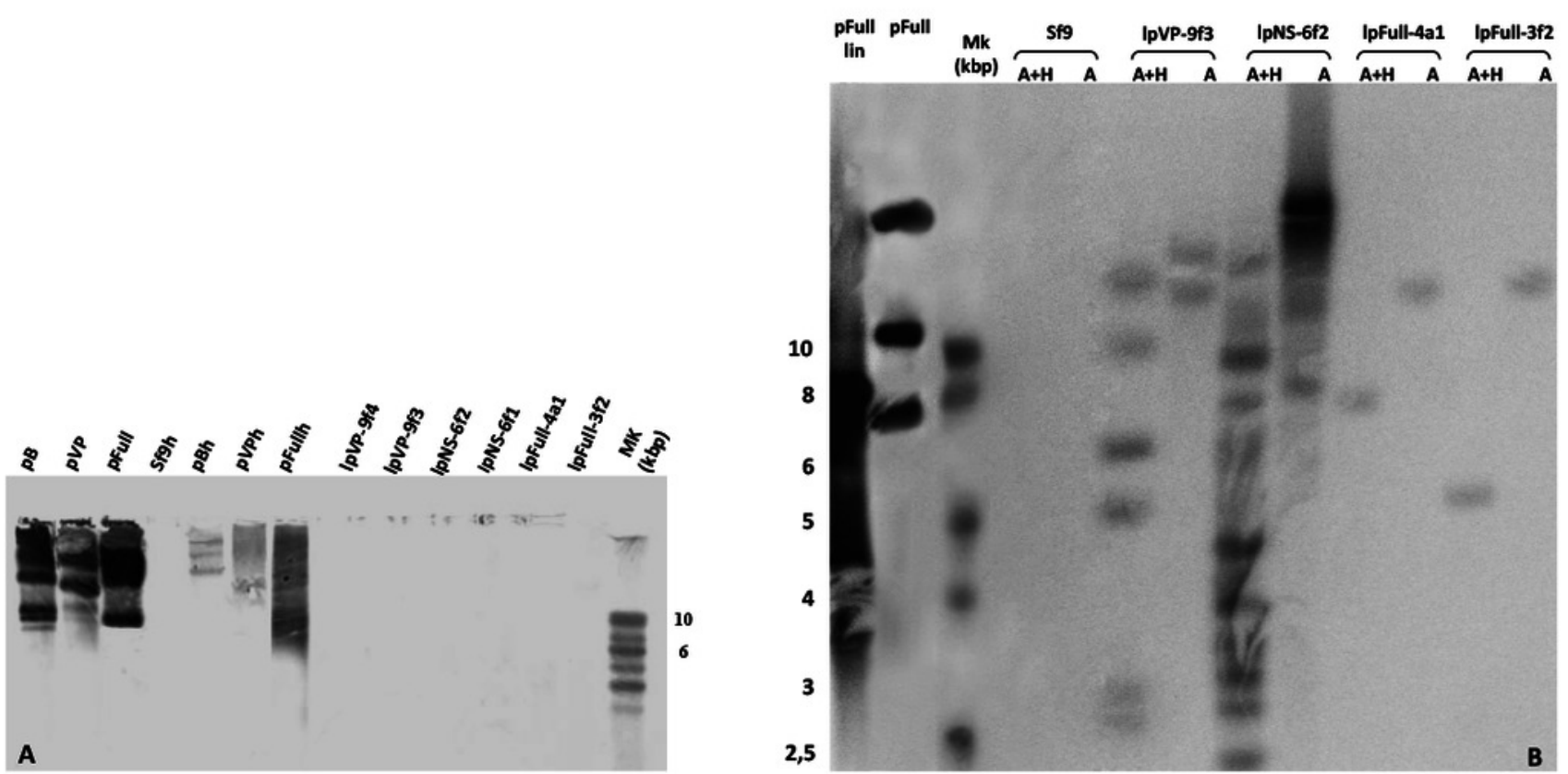


\section{Figure 5}

NS genes sequences are highly rearranged in stable fluorescent cell clones

(A) PCR amplification of the VP-GFP region with primers 1 and 2 (see Table I, Figure 1 ) from IpFull and IpVP clones. (B) Amplification of the large p9 ITR-NS region using primers pair 1', 4. (C) Amplification of the NS-GFP region using primers pair 3, 4. (D) Amplification of ORF2, ORF3 and ORF4 RNA transcripts by RT-PCR using primers in the untranslated region (UTR) upstream the NS-3 ATG codon and the NS-1 region (see Table I). Molecular weight marker (Mk) band sizes are shown on each gel. pFull was used as positive control. Sf9 DNA was used as a negative control.
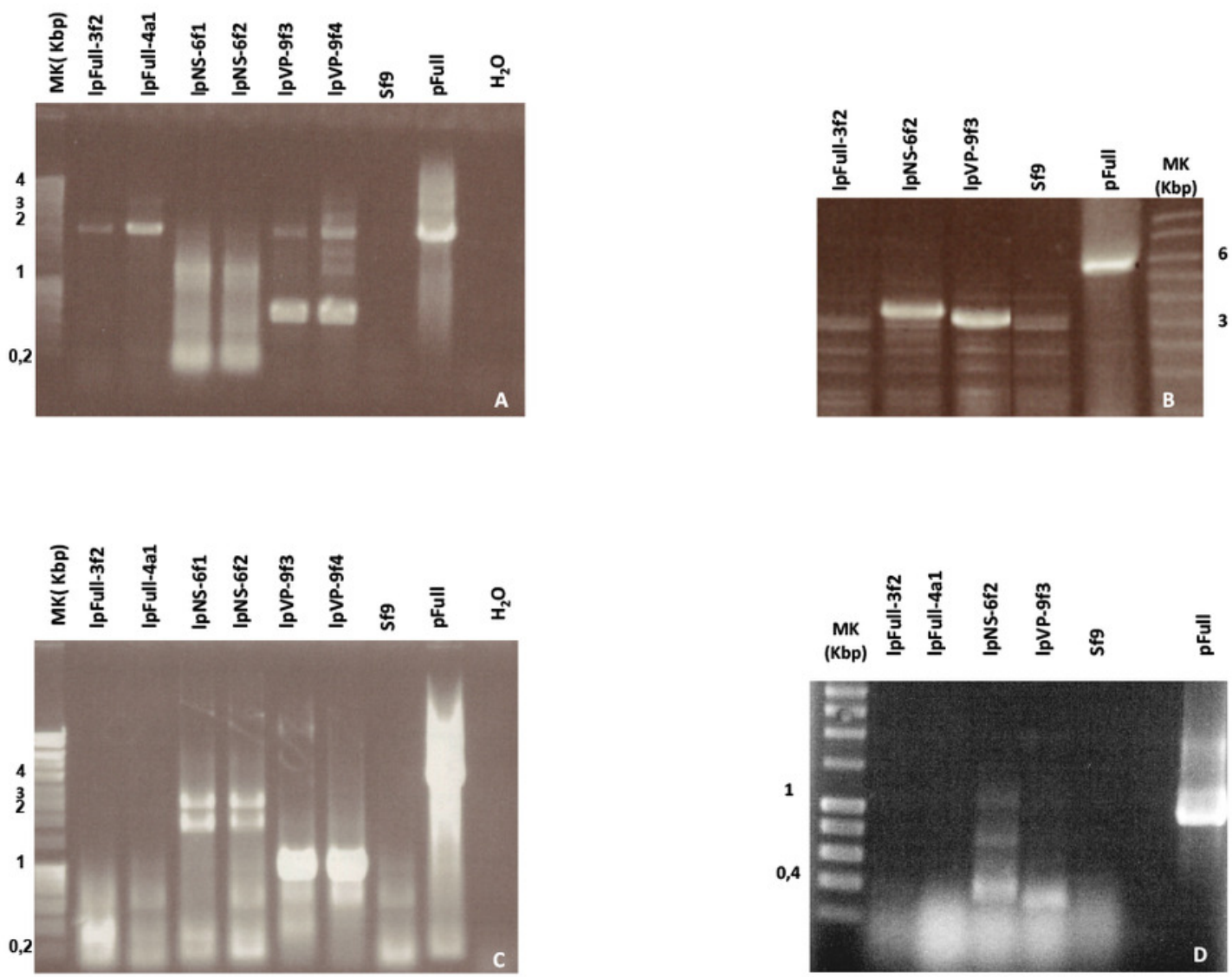


\section{Figure 6 (on next page)}

Schematic representation of viral and genomic DNA sequences identified in our experiments

Raw sequences obtained after numerous amplifications of viral-genomic junctions (suppl. material) where aligned against i) the sequence of the transfected linear plasmid using the discontiguous megablast conditions, ii) the $\mathrm{nr} / \mathrm{nt}$ nucleotide collection specified to Spodoptera frugiperda (taxid 7108), using the blastn conditions. Only the cleaned sequences are represented and motifs identify contiguous sequences from the same amplified sequence, named on the right. (A) BLAST-based alignment against IpFull of raw sequences obtained after amplifications of viral junctions from IpFull-transfected cells. The open diamond represents the location of $\sim 20$ nts from the Bac 68E14 from S. frugiperda [id:681381.1] as a significative example of the rearrangement. (B) BLAST-based alignment against IpVP of raw sequences obtained after amplifications of viral junctions from IpVP-transfected cells. The triangle represents $70 \mathrm{nts}$ of BAC 75E05 from S. frugiperda [id: 681368.1] flanking a $40 \mathrm{nts}$ fragment of the ITR (2-40) and the ellipse represents 70nts of the same BAC intercalated between a JcDV VP fragment (3829-3531) and the NS-ITR boundary (771-551) (C) BLAST alignment against IpNS of raw sequences obtained after amplifications of viral junctions from IpNS-transfected cells. 

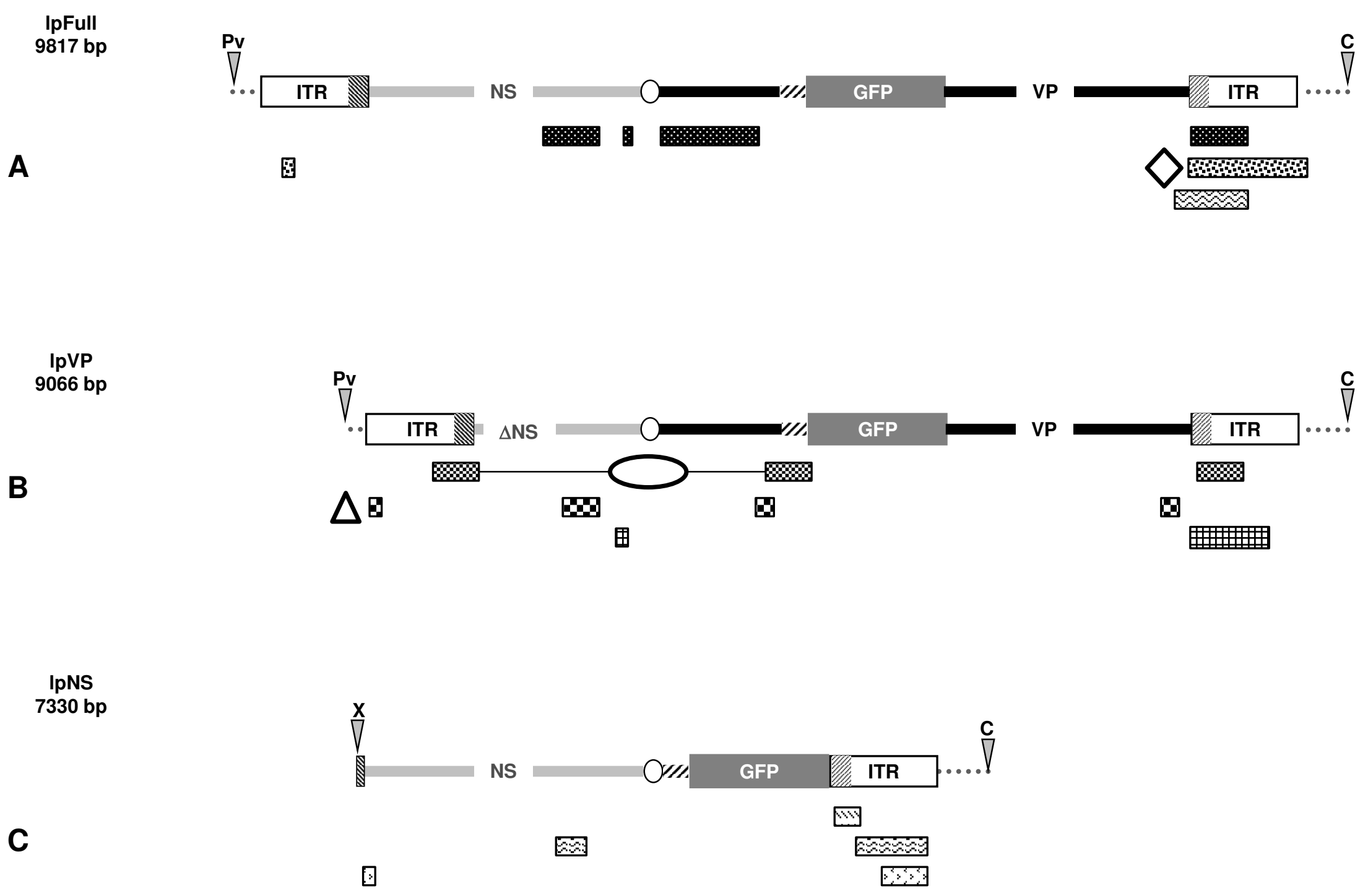


\section{Figure 7}

JCDV NS proteins do not transactivate the p9 promoter in vitro

IPLB-Ld652 permissive cells were co-transfected with plasmid vectors expressing JCDV NS-1, NS-2 and NS-3, respectively and a reporter plasmid adapted to place the expression of the Firefly luciferase gene under the control of p93 promoter. The assay was matched against the renilla luciferase stable expression. Firefly luciferase activity was measured as indicated in the Material and Methods section. Three independent experiments were performed and the significance of the results was assessed after a Student's test (R suite).

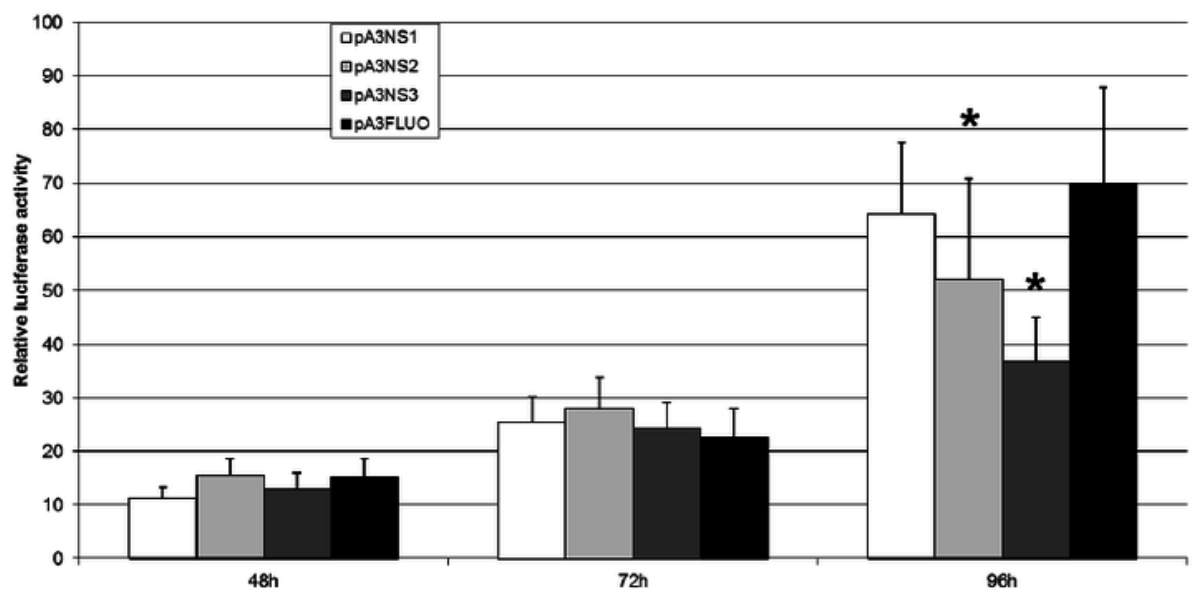




\section{Table $\mathbf{1}$ (on next page)}

Primers used in PCR, RT-PCR, Reverse PCR and Walk PCR analysis 


\begin{tabular}{|c|c|c|}
\hline Analysis & Primer & Sequence \\
\hline PCR (VP-GFP) & $\begin{array}{l}1 \\
2\end{array}$ & $\begin{array}{l}\text { 5'-TAGTCAGTATGTCTTTCTACACGGC-3' } \\
\text { 5'-AACGGTGGTTTAATTAAACCC-3' }\end{array}$ \\
\hline PCR (ITR-GFP) & $\begin{array}{l}1^{\prime} \\
2^{\prime}\end{array}$ & $\begin{array}{l}\text { 5'-GTGACCTCGTTTGACCGGC-3' } \\
\text { 5'-GCTGAACTTGTGGCCGTTTAC-3' }\end{array}$ \\
\hline PCR (NS-GFP) & $\begin{array}{l}3 \\
4\end{array}$ & $\begin{array}{l}\text { 5'-GCATGGACGAGCTGTACAAG-3' } \\
\text { 5'-GTTTCTTTGTGTTCGTCGTTTATTTG-3' }\end{array}$ \\
\hline RT-PCR (NS) & $\begin{array}{l}5 \\
6\end{array}$ & $\begin{array}{l}\text { 5'-CGTCCAAACATTGATCACGGAGCTG-3' } \\
\text { 5'-GTAGTGTTGTGCAAAAGTGGTTCCAGA-3' }\end{array}$ \\
\hline Reverse PCR & 11 & 5'-GGTCAAACGAGGTCACAATAACAAGA-3' \\
\hline $\begin{array}{l}\text { WalkPCR } \\
\text { (Adaptor sequences) }\end{array}$ & $\begin{array}{l}\text { ADPR1 } \\
\text { ADPR2 }\end{array}$ & $\begin{array}{l}\text { 5'-CTAATACGACTCACTATAGGGCTCGAGCGGCCGCCCGGGGAGGT-3' } \\
\text { 5' P-ACCTCCCC-3'NH2 }\end{array}$ \\
\hline (Adaptor primers) & $\begin{array}{l}\text { AP1 } \\
\text { AP2 }\end{array}$ & $\begin{array}{l}\text { 5'-GGATCCTAATACGACTCACTATAGGGC-3' } \\
\text { 5'-CTATAGGGCTCGAGCGGC-3' }\end{array}$ \\
\hline (P9-ITR region) & $\begin{array}{l}13 \\
12\end{array}$ & $\begin{array}{l}\text { 5'-CTGTTTTTGCACACGGCCCAG-3' } \\
\text { 5'-CCAGCCTCGACGCGAGTTTG-3' }\end{array}$ \\
\hline (ITR region) & $\begin{array}{l}10 \\
9 \\
8 \\
7\end{array}$ & $\begin{array}{l}\text { 5'-GCCGGTCAAACGAGGTCAC-3' } \\
\text { 5'-GCTATCTCGCTCTAACAGTTGC-3' } \\
\text { 5'-CTCGCACACTATTGCTGTCCTTC-3' } \\
\text { 5'-CAGCTCCAAGGTCTTCGGATC-3' }\end{array}$ \\
\hline (VP1region) & $\begin{array}{l}15 \\
14 \\
19\end{array}$ & $\begin{array}{l}\text { 5'-CCAAGTTCAATATCTTCAGTAGCAGTAC-3' } \\
\text { 5'-GATGTATTAACCCGGCCGTGTA-3' } \\
\text { 5'-CCTATGATTCCCACTGCTACTAGT-3' }\end{array}$ \\
\hline $\begin{array}{l}\text { (GFP region) } \\
\text { (NS3 region) } \\
\text { (UTR region) }\end{array}$ & $\begin{array}{l}16 \\
17 \\
18\end{array}$ & $\begin{array}{l}\text { 5'-GCAGCTTATAATGGTTACAAATAAAGC-3' } \\
\text { 5'-CAAATAAACGACGAACACAAAGAAAC-3' } \\
\text { 5'-TCACTGAGATGTTCACTCGAC-3' }\end{array}$ \\
\hline
\end{tabular}

